\title{
DETEKSI DINI KEBAKARAN HUTAN DAN LAHAN MEMANFAATKAN EKSTRAKSI EXIF PADA INFORMASI GAMBAR BERBASIS PENGOLAHAN CITRA
}

\author{
Rizal Endar Wibowo ${ }^{\mathrm{a}, 1, *}$, Rony Teguh ${ }^{\mathrm{b}, 2}$, Ariesta Lestari ${ }^{\mathrm{c}, 3}$

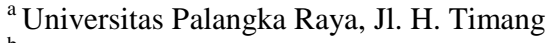 \\ ${ }^{\mathrm{b}}$ Universitas Palangka Raya, Jl. H. Timang \\ ${ }^{\mathrm{c}}$ Universitas Palangka Raya, Jl. H. Timang \\ ${ }^{1}$ rizalendar.re@gmail.com*; ${ }^{2}$ ronnyteguh@gmail.com; ${ }^{3}$ aries22ta@gmail.com \\ * corresponding author
}

ARTICLE INFO

Keywords

Forest and land fires

EXIF Extraction

Image Processing

Color filtering
ABSTRACT

Forest fire detection system is one of important tools in preventing and mitigating forest and land fires. In Indonesia, the detection of forest and land fires relies on hotspot information captured from satellites. However, the location obtained by the satellite has a horizontal error of $2 \mathrm{~km}$ from the ground check data. Therefore, these information are less relevant to the actual location.

In this research, an android app is proposed to extract Exchangeable Image Format (EXIF) photo metadata. The metadata has image information such as latitude and longitude, to obtain the location of forest fires reported by the application user. In addition, this research implemented one of the image processing methods to classify fire and smoke in images of fires. Color filtering method is used based on the color space of Red Green Blue (RGB), Hue Saturation Value (HSV) and $\mathrm{YCbCr}$. This classification process aims to ease the burden on the admin in confirming user reports.

The results of the fire and smoke classification process are described using a confusion matrix. This matrix produces an accuracy rate of $75 \%$, a precision of $80 \%$ and a recall of $80 \%$ for a fire classification and an accuracy of $70 \%$, a precision of $92 \%$ and a recall of $87 \%$ for smoke classification. There are $25 \%$ and $30 \%$ of misclassified data of fire and smoke. This is because the color filtering method classifies each color pixel from the image, therefore many pixels that are not classified as fire or smoke images are classified because there are other objects that have a range of colors to classify fire and smoke.

\section{Pendahuluan}

Deteksi dini kebakaran hutan di Indonesia sampai saat ini hanya berdasarkan informasi titik panas atau hotspot yang berasal dari satelit, yaitu satelit NOAA (National Oceanic and Athmospheric Administration) dan satelit MODIS (Moderate Resolution Imaging Spectroradiometer). Berdasarkan pernyataan Satuan Tugas (SATGAS) bencana Lembaga Penerbangan Dan Antariksa Nasional (LAPAN), satelit-satelit tersebut hanyalah mendeteksi hotspot atau titik panas. Hotspot merupakan satu area yang memiliki suhu relatif lebih tinggi dibandingkan dengan sekitarnya yang dapat dideteksi oleh satelit. Secara kualitas titik panas yang banyak menunjukkan adanya kebakaran hutan atau lahan disuatu wilayah, namun secara ilmiah masih terdapat kesalahan yang masih perlu diperhatikan, salah satunya menunjukkan bahwa error horizontal hotspot adalah sekitar $1 \mathrm{~km}-2 \mathrm{~km}$ dari koordinat yang ditunjukkan satelit [1]. Dengan adanya error ini tentu mengakibatkan penanganan terhadap kebakaran hutan menjadi lebih lambat karena titik koordinat yang didapatkan kurang sesuai dengan titik api di lokasi sebenarnya. Peran serta masyarakat dapat membantu memberikan informasi mengenai 
dengan titik koordinat yang tidak jauh berbeda dengan lokasi sebenarnya. Sehingga dibutuhkan suatu aplikasi yang dapat digunakan oleh masyarakat untuk dapat memiliki peran dalam memberikan informasi kebakaran hutan.

Salah satu bukti terjadinya kebakaran adalah adanya foto kejadian kebakaran yang diambil oleh masyarakat. Dalam foto dapat di ambil metadata yang biasa disebut Exchangeable Image Format (EXIF). EXIF merupakan suatu tempat yang digunakan untuk menyimpan metadata dalam suatu foto. Dimana data yang tersimpan seperti informasi tentang kamera (model, pembuat dan serial number) dan pengaturan (shuttle speed, focal length, resolusi, tanggal dan waktu). Sebagai tambahan, jika kamera memiliki kapabilitas Global Positioning System (GPS), data latitude dan longitude dari lokasi akan terekam kedalam bagian EXIF dari sebuah file gambar [2]. Metadata GPS dalam EXIF bisa didapatkan dengan memanfaatkan fitur geotagging. Geotagging dapat menggabungkan kamera ponsel yang dapat melakukan sinergi langsung dengan fitur GPS.

Foto yang didapatkan tidak semuanya merupakan kebakaran hutan. Hal ini dikarenakan ada kemungkinan laporan yang diberikan merupakan laporan palsu. Foto yang menunjukan kebakaran hutan umumnya memiliki api dan asap didalamnya. Kemudian untuk mendeteksi api dan asap dalam foto dapat mengunakan pengolahan citra. Pengolahan citra yang dapat digunakan adalah color filtering. Color filtering adalah suatu teknik pengolahan citra yang dipakai untuk memanipulasi suatu citra berdasarkan warna spesifik. Cara kerjanya adalah dengan membandingkan komponen warna setiap setiap piksel citra dengan warna spesifikasi. Ada beberapa ruang warna yang dikenal, antara lain Red, green, blue (RGB), Hue, Saturation and Value (HSV), YCbCr [3].

Beberapa penelitian sebelumnya yang terkait penelitian ini adalah penelitian yang dilakukan oleh A. Mardini [4] telah membuat Sistem Informasi Geografis Pelaporan Masyarakat (SIGMA) Berbasis Foto Geotag untuk mendapatkan koordinat dari laporan masyarakat. A. Susanto [5] telah membuat Sistem Reaksi Cepat Satgas Desa Dalam Pelaporan Kebakaran Lahan dan Hutan Berbasis Android untuk monitoring titik api disekitar wilayahnya dan langsung melakukan update data lewat android. C. E. Premal and S. S. Vinsley [6] telah meneliti tentang pengolahan citra dalam pendeteksian kebakaran hutan menggunakan ruang warna YCbCr. Serta MD. Kamrujjaman Sarker [7] telah meneliti tentang pengolahan citra untuk mendeteksi asap.

\section{Metodologi Penelitian}

Penelitian ini menggunakan data yang didapatkan dari google gambar dengan kata kunci pencarian "kebakaran hutan", dari Pusat Pengendalian Operasi Pengendalian Bencana (Pusdalops PB) BPBD Pulang Pisau serta pengambilan gambar secara langsung menggunakan kamera ponsel. Data yang dikumpulkan yaitu data latih dan data uji. Data latih berjumlah 25 data citra asap dan 25 data citra api serta data uji sebanyak 20 data citra asap dan 20 data citra api.
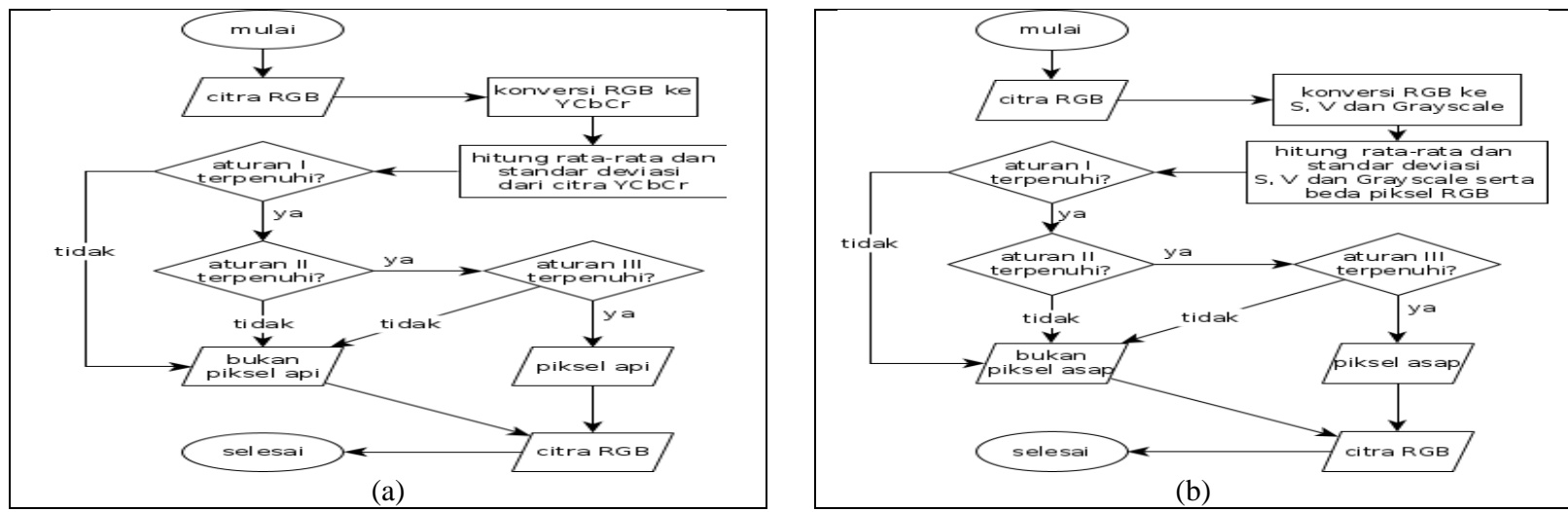

Gambar 1 (a) Flowchart proses klasifikasi citra api; (b) Flowchart proses klasifikasi citra asap 


\section{JURNAL TEKNOLOGI INFORMASI}

Jurnal Keilmutan dan Aplikasi Bjilang Teknik Informatika
[E-ISSN 2656-0321]

[Vol 15 No 1]

[ Januari 2021]

a. Klasifikasi

api untuk deteksi citra kebakaran hutan

Proses yang akan digunakan dapat dilihat pada gambar 3. Aturan-aturan yang akan dibuat adalah berbasis ruang warna karena kesederhanaan dan mudah di implementasikan ke sebuah program. Untuk itu, disini menggunakan salah satu ruang warna yaitu $\mathrm{YCbCr}$.

Konversi RGB ke YCbCr menggunakan persamaan berikut [10].

$$
\left[\begin{array}{c}
Y \\
C b \\
C r
\end{array}\right]=\left[\begin{array}{ccc}
0.2568 & 0.5041 & 0.0979 \\
-0.1482 & -0.2910 & 0.4392 \\
0.4392 & -0.3678 & -0.0714
\end{array}\right]\left[\begin{array}{l}
R \\
G \\
B
\end{array}\right]+\left[\begin{array}{c}
16 \\
128 \\
128
\end{array}\right]
$$

di mana $\mathrm{Y}$ adalah luminance, $\mathrm{Cb}$ dan $\mathrm{Cr}$ masing-masing adalah komponen ChrominanceBlue dan ChrominanceRed [10].

Nilai rata-rata dari tiga komponen $\mathrm{Y}, \mathrm{Cb}$, dan $\mathrm{Cr}$, dilambangkan oleh $Y_{\text {mean }}, C b_{\text {mean }}$ dan $C r_{\text {mean }}$ masing-masing dihitung sebagai berikut [10].

$$
\begin{aligned}
Y_{\text {mean }}(x, y) & =\frac{1}{M \times N} \sum_{x=1}^{M} \sum_{y=1}^{N} Y(x, y) \\
C b_{\text {mean }}(x, y) & =\frac{1}{M \times N} \sum_{x=1}^{M} \sum_{y=1}^{N} \operatorname{Cb}(x, y) \\
C r_{\text {mean }}(x, y) & =\frac{1}{M \times N} \sum_{x=1}^{M} \sum_{y=1}^{N} \operatorname{Cr}(x, y)
\end{aligned}
$$

di mana, (x, y) menunjukkan lokasi spasial piksel, $\mathrm{M} \times \mathrm{N}$ adalah jumlah total piksel dalam gambar yang diberikan [10].

Standar deviasi merupakan nilai statistik yang dapat dimanfaatkan untuk menentukan seberapa dekat titik data individu ke mean dari sampel. Untuk menghitung nilai standar deviasi akan menggunakan persamaan berikut [11].

$$
S=\sqrt{\frac{\sum_{i=1}^{n}\left(x_{i}-x\right)^{2}}{n}}
$$

Kemudian untuk menghitung treshold atau ambang batas dari suatu nilai komponen warna dapat menggunakan persamaan berikut.

$$
\mathrm{T}=\bar{x} \pm s
$$

b. Klasifikasi asap untuk deteksi citra kebakaran hutan

Proses yang akan digunakan dapat dilihat pada gambar 4. Aturan-aturan yang akan dibuat adalah berbasis ruang warna karena kesederhanaan dan mudah di implementasikan ke sebuah program. Untuk itu, disini menggunakan ruang warna yaitu Grayscale dan HSV.

Konversi RGB ke HSV menggunakan persamaan berikut [12].

$\mathrm{R}^{\prime}=\mathrm{R} / 255$

$\mathrm{G}^{\prime}=\mathrm{G} / 255$

$\mathrm{B}^{\prime}=\mathrm{B} / 255$ 
$\left.\mathrm{B}^{\prime}\right)$

$\mathrm{C}_{\min }=\min \left(\mathrm{R}^{\prime}, \mathrm{G}^{\prime}, \mathrm{B}^{\prime}\right)$

$\Delta=\mathrm{C}_{\max }-\mathrm{C}_{\min }$

Kalkulasi nilai Hue :

$$
\mathrm{H}=\left\{\begin{array}{c}
0^{\circ}, \Delta=0 \\
60^{\circ} \times\left(\frac{\mathrm{G}^{\prime}-\mathrm{B}^{\prime}}{\Delta} \bmod 6\right), \mathrm{C}_{\max }=\mathrm{R}^{\prime} \\
60^{\circ} \times\left(\frac{\mathrm{B}^{\prime}-\mathrm{R}^{\prime}}{\Delta}+2\right), \mathrm{C}_{\max }=\mathrm{G}^{\prime} \\
60^{\circ} \times\left(\frac{\mathrm{R}^{\prime}-\mathrm{G}^{\prime}}{\Delta}+4\right), \mathrm{C}_{\max }=\mathrm{B}^{\prime}
\end{array}\right.
$$

Kalkulasi nilai Saturation :

$$
S=\left\{\begin{array}{c}
0, C_{\text {max }}=0 \\
\frac{\Delta}{C_{\max }}, C_{\text {max }} \neq 0
\end{array}\right.
$$

Kalkulasi nilai Value :

$$
\mathrm{V}=\mathrm{C}_{\max }
$$

Konversi RGB ke Grayscale menggunakan persamaan berikut [13].

$$
\text { grayscale }=\frac{R+G+B}{3}
$$

c. Skenario pengujian

Dalam proses ini akan menggunakan 20 data uji api dan 20 data uji asap. Data uji api terdiri dari 5 data citra api kebakaran hutan yang didapatkan dari google gambar, 5 data citra api kebakaran hutan tahun 2019 dari Pusat Pengendalian Operasi Pengendalian Bencana (PUSDALOPS PB) BPBD Pulang Pisau, 5 data citra kebakaran selain kebakaran hutan seperti kebakaran rumah, api hasil pembakaran sampah dan lain sebagainya serta 5 data sisanya yaitu citra langit sore, citra langit pagi, citra matahari siang, citra objek warna merah dan objek warna merah kekuningan.

Kemudian untuk data uji asap menggunakan 5 data citra asap kebakaran hutan yang didapatkan dari google gambar, 5 data citra asap kebakaran hutan tahun 2019 dari Pusat Pengendalian Operasi Pengendalian Bencana (PUSDALOPS PB) BPBD Pulang Pisau, 5 data citra asap kebakaran selain kebakaran hutan seperti asap kebakaran rumah, asap hasil pembakaran sampah dan lain sebagainya serta 5 data sisanya yaitu citra awan dan beberapa objek yang memiliki komponen warna putih keabuan.

Hasil dari pengujian akan digambarkan dalam confusion matrix. Confusion matrix dapat memberikan informasi perbandingan hasil klasifikasi yang dilakukan oleh sistem (model) dengan hasil klasifikasi sebenarnya. Confusion matrix dapat digunakan dalam menghitung berbagai performance metrics untuk mengukur kinerja model yang telah dibuat.Terdapat beberapa performance metrics populer yang umum dan sering digunakan: accuracy, precission, dan recall [8].

$$
\text { accuracy }=\frac{T P+T N}{T P+T N+F P+F N}
$$




\section{JURNAL TEKNOLOGI INFORMASI}

$$
\text { recall }=\frac{T P}{T P+F N}
$$

\section{Hasil dan Pembahasan}

a. Klasifikasi api

\section{1) Input citra RGB}

Untuk input-an ini menggunakan hasil segmentasi manual dari data citra api kebakaran hutan yang telah dikumpulkan. Berikut beberapa citra tersebut.

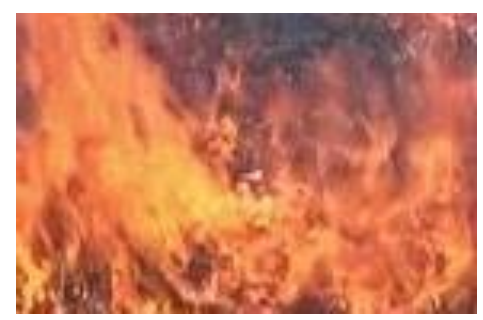

(a)

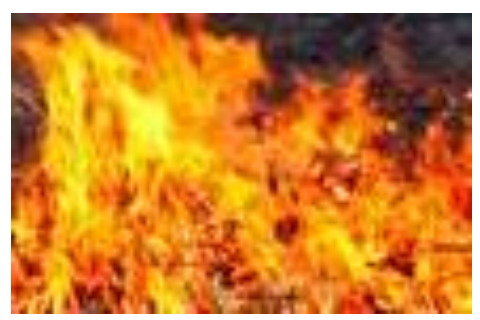

(b)

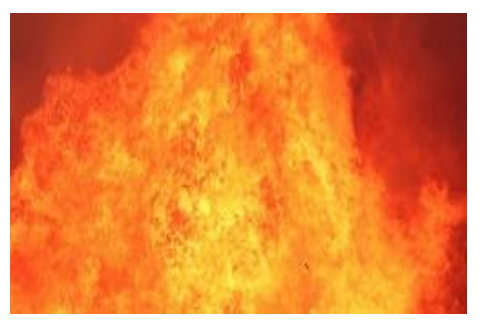

(c)

Gambar 2 Beberapa sampel citra RGB api

\section{2) Konversi RGB ke YCbCr}

Proses konversi dilakukan menggunakan persamaan (1). Proses ini dilakukan dengan tujuan untuk mendapatkan nilai $\mathrm{Y}, \mathrm{Cb}$ dan $\mathrm{Cr}$. Dimana nilai ini dapat digunakan untuk menentukan aturan-aturan yang akan digunakan untuk proses klasifikasi api citra kebakaran hutan.

3) Hitung rata-rata dan standar deviasi dari citra $\mathrm{YcbCr}$

Tabel 1 Nilai rata-rata dan standar deviasi YCbCr dari dataset sampel api.

\begin{tabular}{|c|c|c|c|c|c|c|}
\hline \multirow{2}{*}{ Gambar } & $\mathbf{Y}_{\text {mean }}$ & $\mathbf{C b}_{\text {mean }}$ & $\mathbf{C r}_{\text {mean }}$ & $\mathbf{S}_{\mathbf{Y}}$ & $\mathbf{S}_{\mathbf{C b}}$ & $\mathbf{S}_{\mathbf{C r}}$ \\
\hline 1 & 134,705 & 101,043 & 167,739 & 27,840 & 13,980 & 12,558 \\
\hline 2 & 132,316 & 75,412 & 172,335 & 45,057 & 27,289 & 19,190 \\
\hline 3 & 140,443 & 77,073 & 184,519 & 33,990 & 14,906 & 12,595 \\
\hline
\end{tabular}

4) Aturan I

Dari hasil perhitungan rata-rata dan standar deviasi $\mathrm{YCbCr}$ dari keseluruhan dataset sampel api menunjukan bahwa nilai Y selalu lebih besar dari $\mathrm{Cb}$ dan nilai $\mathrm{Cr}$ selalu lebih besar pula dari $\mathrm{Cb}$. Sehingga untuk aturan I didapatkan persamaan sebagai berikut.

$$
\mathrm{R}_{\text {Api } 1}= \begin{cases}1, & \text { Jika }(\mathrm{Y}>\mathrm{Cb} \cap \mathrm{Cr}>\mathrm{Cb}) \\ 0, & \text { Jika kondisi diatas tidak terpenuhi }\end{cases}
$$


Daerah nyala api pada umumnya merupakan daerah yang paling terang dari suatu kebakaran hutan sehingga nilai $\mathrm{Y}_{\text {mean, }} \mathrm{Cb}_{\text {mean }}$ dan $\mathrm{Cr}_{\text {mean }}$ memiliki nilai berharga. Untuk itu pada aturan ini akan di analisa perbedaan nilai komponen $\mathrm{Y}, \mathrm{Cb}$ dan $\mathrm{Cr}$ apakah lebih besar dari atau lebih kecil dari nilai $\mathrm{Y}_{\text {mean, }} \mathrm{Cb}_{\text {mean }}$ dan $\mathrm{Cr}_{\text {mean }}$ sampel tersebut.

Tabel 2 Perbandingan nilai $\mathrm{Y}, \mathrm{Cb}$ dan $\mathrm{Cr}$ terhadap $\mathrm{Y}_{\text {mean, }} \mathrm{Cb}_{\text {mean }}$ dan $\mathrm{Cr}_{\text {mean }}$ dari dataset sampel api

\begin{tabular}{|c|c|c|c|c|c|c|}
\hline & $\mathbf{A}(\%)$ & B $(\%)$ & $\mathrm{C}(\%)$ & $\mathrm{D}(\%)$ & $\mathrm{E}(\%)$ & $\mathbf{F}(\%)$ \\
\hline $\begin{array}{c}\text { Rata-rata } \\
\text { keseluruhan } \\
\text { data latih }\end{array}$ & 54,79 & 45,21 & 46,20 & 53,80 & 52,90 & 47,10 \\
\hline
\end{tabular}

Keterangan : $\mathrm{A}=\mathrm{Y}>\mathrm{Y}_{\text {mean }} ; \mathrm{B}=\mathrm{Y}<\mathrm{Y}_{\text {mean }} ; \mathrm{C}=\mathrm{Cb}>\mathrm{Cb}_{\text {mean }} ; \mathrm{D}=\mathrm{Cb}<\mathrm{Cb}_{\text {mean }} ; \mathrm{E}=\mathrm{Cr}>\mathrm{Cr}_{\text {mean }} ; \mathrm{F}=$ $\mathrm{Cr}<\mathrm{Cr}_{\text {mean }}$

Dari tabel 2 dapat diamati bahwa rata-rata dari nilai Y pada keseluruhan piksel pada dataset api memiliki nilai yang lebih besar dari $\mathrm{Y}_{\text {mean }}$ yaitu sebesar 54,79\% sedangkan nilai $\mathrm{Cb}$ cenderung memiliki nilai yang lebih kecil dari $\mathrm{Cb}_{\text {mean }}$ yaitu sebesar $53,80 \%$. Kemudian nilai $\mathrm{Cr}$ dari dataset sampel memiliki nilai yang lebih besar dibandingkan dengan nilai $\mathrm{Cr}_{\text {mean }}$ yaitu 52,90\%.

$$
R_{\text {Api } 2}=\left\{\begin{array}{c}
\text { Jika }\left(Y_{(x, y)}>Y_{\text {mean }} \cap\right. \\
C b_{(x, y)}<C b_{\text {mean }} \cap \\
\left.C r_{(x, y)}>C r_{\text {mean }}\right) \\
0, \quad \text { Jika kondisi diatas tidak terpenuhi }
\end{array}\right.
$$

6) Aturan III

Tabel 3 Nilai rata-rata dari keseluruhan data latih

\begin{tabular}{|c|c|c|c|c|c|c|}
\cline { 2 - 6 } & $\mathbf{Y}_{\text {mean }}$ & $\mathbf{C b}_{\text {mean }}$ & $\mathbf{C r}_{\text {mean }}$ & $\mathbf{S}_{\mathbf{Y}}$ & $\mathbf{s}_{\mathbf{C b}}$ & $\mathbf{s}_{\mathbf{C r}}$ \\
\hline $\begin{array}{c}\text { Rata-rata } \\
\text { keseluruhan data } \\
\text { latih }\end{array}$ & 152,884 & 84,355 & 171,504 & 27,828 & 13,476 & 12,539 \\
\hline
\end{tabular}

Dalam menentukan piksel api, nilai standar deviasi dapat digunakan untuk menentukan nilai ambang batas dari piksel terhadap rata-rata nilai Y, Cb dan Cr. Dari dua aturan sebelumnya dapat disimpulkan bahwa semakin tinggi komponen Y maka semakin baik untuk proses pendeteksian api karena komponen Y mewakili luminance atau pencahayaan pada citra. Kemudian semakin rendah komponen $\mathrm{Cb}$ maka semakin baik karena $\mathrm{Cb}$ mewakili ChrominanceBlue atau tingkat kebiruan citra dan semakin tinggi komponen $\mathrm{Cr}$ maka semakin baik karena $\mathrm{Cr}$ mewakili ChrominanceRed atau tingkat kebiruan citra. Sehingga untuk didapatkan nilai tresshold untuk masing - masing komponen dapat menggunakan persamaan (6).

Maka untuk aturan III didapatkan persamaan sebagai berikut. 


\section{JURNAL TEKNOLOGI INFORMASI}

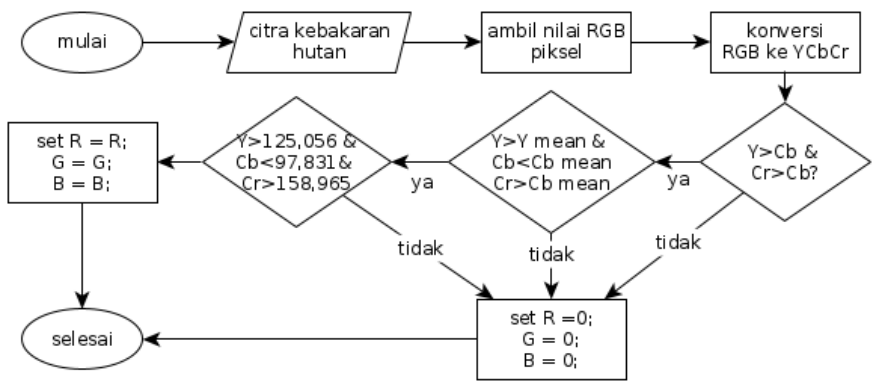

Gambar 3 Flowchart proses klasifikasi api

b. Klasifikasi asap

1) Input citra RGB

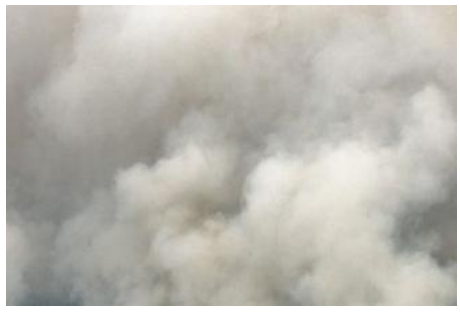

(a)

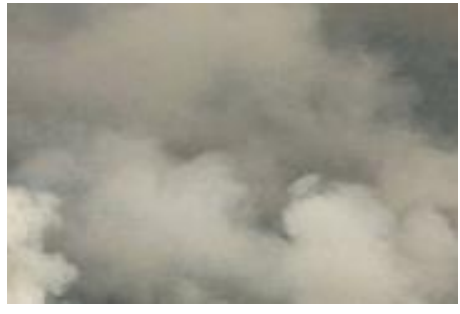

(b)

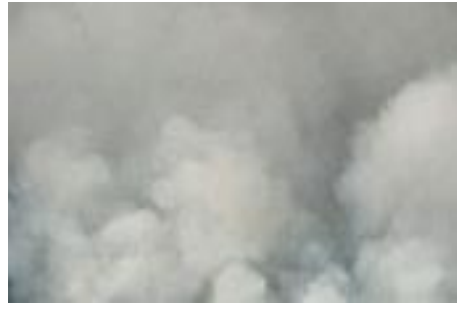

(c)

Gambar 4 Beberapa sampel citra RGB asap

2) Konversi RGB ke S, V dan grayscale

Proses konversi dilakukan menggunakan persamaan (8), (9) dan (10). Proses ini dilakukan dengan tujuan untuk mendapatkan nilai S, V dan grayscale. Dimana nilai ini dapat digunakan untuk menentukan aturan-aturan yang akan digunakan untuk proses klasifikasi asap citra kebakaran hutan.

3) Hitung rata-rata dan standar deviasi dari nilai $|\mathrm{RG}|,|\mathrm{RB}|,|\mathrm{GB}|, \mathrm{S}, \mathrm{V}$ dan grayscale

Tabel 4 Rata-rata dari nilai |RG|, |RB|, |GB|, S, V dan grayscale

\begin{tabular}{|c|c|c|c|c|c|c|}
\hline Gambar & $\overline{\boldsymbol{X}}$ Grayscale & $\overline{\boldsymbol{X}} \mathbf{S}$ & $\overline{\boldsymbol{X}} \mathbf{~ V}$ & $\overline{\boldsymbol{X}}|\mathbf{R G}|$ & $\overline{\boldsymbol{X}}|\mathbf{R B}|$ & $\overline{\boldsymbol{X}}|\mathbf{G B}|$ \\
\hline 1 & 180,360 & 0,057 & 0,725 & 2,401 & 10,230 & 7,828 \\
\hline 2 & 148,597 & 0,101 & 0,608 & 2,792 & 15,594 & 12,802 \\
\hline 3 & 168,524 & 0,038 & 0,672 & 2,690 & 2,703 & 5,393 \\
\hline$\vdots$ & $\vdots$ & $\vdots$ & $\vdots$ & $\vdots$ & $\vdots$ & $\vdots$ \\
\hline 25 & 155,568 & 0,127 & 0,685 & 2,756 & 21,976 & 19,221 \\
\hline & Rata-rata & $\mathbf{0 , 1 0 7}$ & $\mathbf{0 , 6 8 0}$ & $\mathbf{6 , 5 4 1}$ & $\mathbf{1 7 , 1 3 9}$ & $\mathbf{1 1 , 2 4 4}$ \\
\hline
\end{tabular}




\section{JURNAL TEKNOLOGI INFORMASI}

\begin{tabular}{|c|c|c|c|c|c|c|}
\hline Gambar & S Grayscale & S S & S V & s |RG & S |RB & S |GB $\mid$ \\
\hline 1 & 26,515 & 0,023 & 0,107 & 2,747 & 5,200 & 3,341 \\
\hline 2 & 23,801 & 0,022 & 0,099 & 2,773 & 5,335 & 3,149 \\
\hline 3 & 17,704 & 0,012 & 0,070 & 2,862 & 4,425 & 2,145 \\
\hline$\vdots$ & $\vdots$ & $\vdots$ & $\vdots$ & $\vdots$ & $\vdots$ & $\vdots$ \\
\hline 25 & 17,143 & 0,015 & 0,071 & 2,977 & 3,784 & 1,663 \\
\hline \multicolumn{2}{|c|}{ Rata-rata } & $\mathbf{0 , 0 3 7}$ & $\mathbf{0 , 0 9 5}$ & $\mathbf{3 , 9 8 9}$ & $\mathbf{8 , 1 1 3}$ & $\mathbf{4 , 9 1 2}$ \\
\hline
\end{tabular}

4) Aturan I

Dari hasil nilai rata-rata grayscale didapatkan nilai rata-rata terkecil yaitu 125,455 dengan standar deviasi sebesar 51,076. Kemudian nilai rata-rata terbesar yaitu 220,714 dengan standar deviasi sebesar 18,595. Nilai ini digunakan sebagai ambang batas minimal dan maksimal piksel asap. Sehingga untuk aturan I menggunakan persamaan berikut.

$$
R_{\text {Asap } 1}=\left\{\begin{array}{cc}
1, & \text { Jika }(\operatorname{Grayscale}(x, y) \geq 74 \cap \operatorname{Grayscale}(x, y) \leq 240 \\
0, & \text { Jika kondisi diatas tidak terpenuhi }
\end{array}\right.
$$

\section{5) Aturan II}

Tabel 5 dan 6 memperlihatkan hasil dari perhitungan $|\mathrm{RG}|,|\mathrm{RB}|$ dan $|\mathrm{GB}|$ dari dataset sampel asap. Dari nilai rata-rata pada masing-masing tabel maka didapatkan nilai ambang batas yang dihitung menggunakan persamaan (6). nilai tersebut akan digunakan untuk aturan II. Sehingga untuk aturan II menggunakan persamaan berikut.

$$
R_{\text {Asap } 2}=\left\{\begin{array}{cc}
1, & \text { Jika }(|R G|(x, y) \leq 11 \cap|R B|(x, y) \leq 25 \cap|G B|(x, y) \leq 16 \\
0, & \text { Jika kondisi diatas tidak terpenuhi }
\end{array}\right.
$$

6) Aturan III

Untuk menghitung ambang batas dari asap dapat menggunaan persamaan berikut [7]

$$
\mathrm{T}=\mu+2 \times \partial
$$

dimana $T$ merupakan ambang batas atau treshold, $\mu$ adalah rata-rata nilai mean dan $\partial$ adalah ratarata nilai standar deviasi. Untuk tabel 5 dan 6 didapatkan nilai $\mathrm{T}$ sebagai berikut.

$$
\begin{aligned}
& \mathrm{T}_{\mathrm{S}}=0,107+2 \times 0,037=0,181 \\
& \mathrm{TV}=0,680+2 \times 0,095=0,870
\end{aligned}
$$

Karena semakin tinggi nilai dari $\mathrm{V}$ maka citra semakin gelap maka nilai untuk mengklasifikasi asap harus lebih rendah atau sama dengan nilai $\mathrm{T}_{\mathrm{V}}$. Untuk nilai $\mathrm{S}$ harus lebih rendah dari $T_{S}$ karena semakin rendah nilai $S$ maka semakin jernih warna keabuan yang didapat. Sehingga untuk aturan asap ketiga menggunakan persamaan sebagai berikut.

$$
R_{\text {Asap } 3}=\left\{\begin{array}{l}
1, \quad \text { Jika }\left(S(x, y) \leq T_{S} \cup V(x, y) \leq T_{V}\right. \\
0, \quad \text { Jika kondisi diatas tidak terpenuhi }
\end{array}\right.
$$




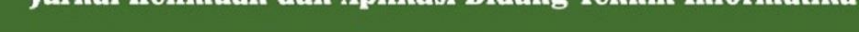

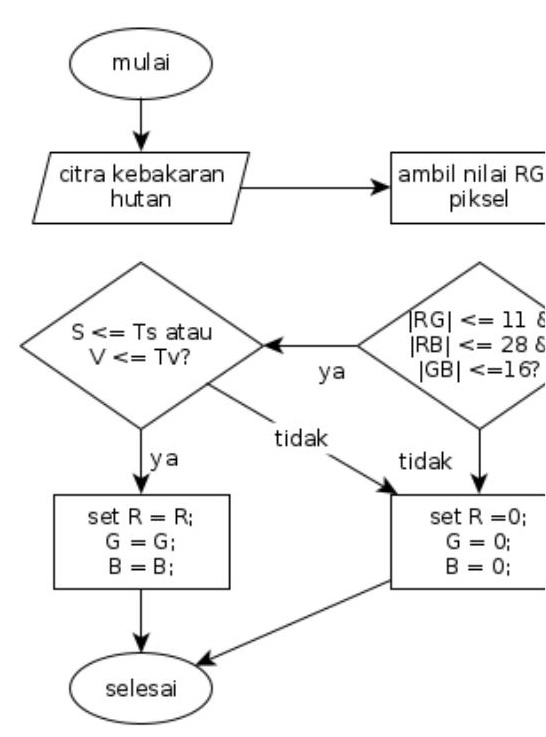

Gambar 5 Flowchart proses klasifikasi asap

c. Skenario pengujian

1) Hasil pengujian klasifikasi api

Pengujian klasifikasi api terdiri dari 20 dataset data uji dimana 15 data memiliki piksel api didalamnya dan 5 data yang tidak memiliki piksel api sama sekali didalamnya. Gambar 10 merupakan salah satu citra yang melalui proses tahapan-tahapan dalam proses klasifikasi api.

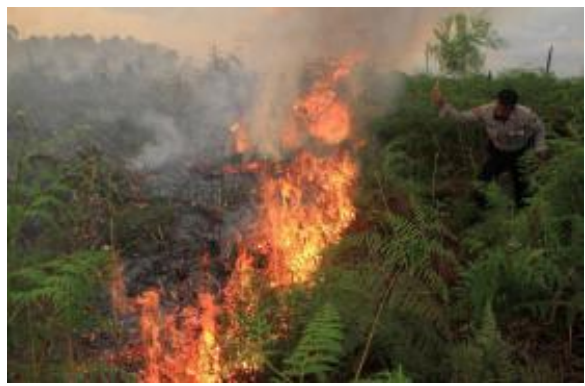

(a)

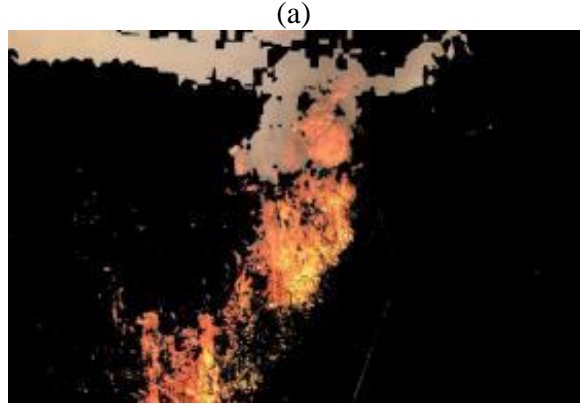

(c)

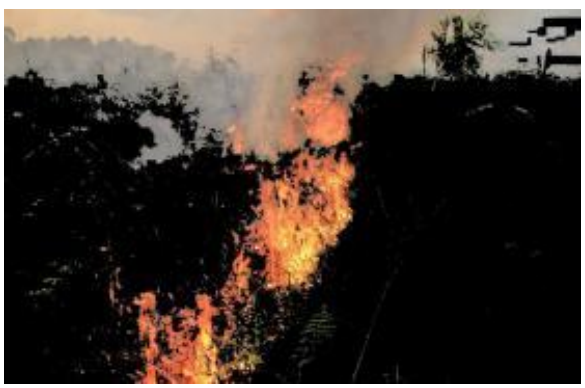

(b)

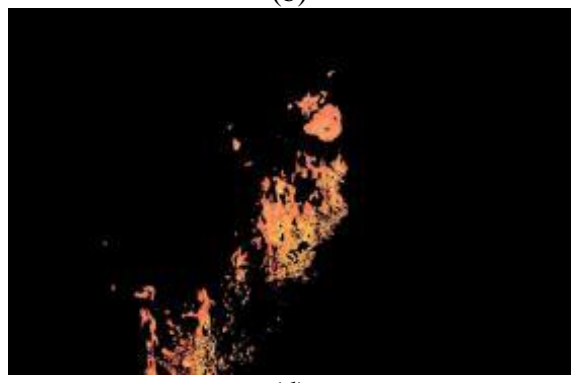

(d)

Gambar 6 (a) Citra api asli; (b) Output Aturan I; (c) Output Aturan II; (d) Output Aturan III

Hasil dari dari seluruh pengujian ini terlihat dalam tabel confusion matrix berikut.

Tabel 6 Confusion matrix hasil pengujian klasifikasi api 


\section{JURNAL TEKNOLOGI INFORMASI}

Jurnal Keilmutan dan Aplikasi Bidang Teknik Iniormatika

[E-ISSN 2656-0321]

[Vol 15 No 1]

[ Januari 2021]

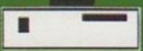

\begin{tabular}{|c|c|c|c|}
\hline & & True & False \\
\hline \multirow{2}{*}{ 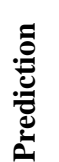 } & True & 12 & 2 \\
\hline & False & 3 & 3 \\
\hline
\end{tabular}

2) Hasil pengujian klasifikasi citra asap

$$
\begin{gathered}
\text { accuracy }=\frac{12+3}{12+3+2+3}=\frac{15}{20}=0,75=75 \% \\
\text { precision }=\frac{12}{12+3}=\frac{12}{15}=0,8=80 \% \\
\text { recall }=\frac{12}{12+3}=\frac{12}{15}=0,8=80 \%
\end{gathered}
$$

Pengujian klasifikasi asap terdiri dari 20 dataset data uji dimana 15 data memiliki piksel asap didalamnya dan 5 data yang tidak memiliki piksel asap sama sekali didalamnya. Gambar 11 merupakan salah satu citra yang melalui proses tahapan-tahapan dalam proses klasifikasi asap.

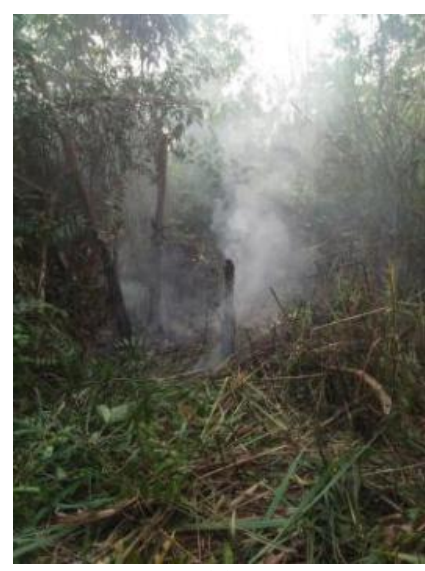

(a)

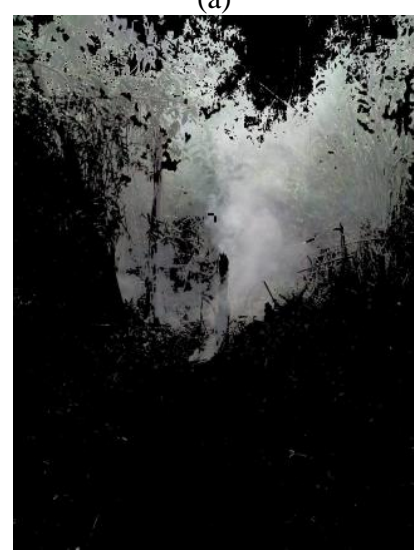

(c)

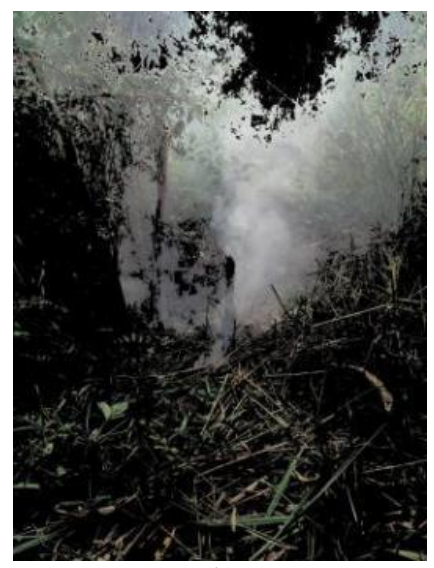

(b)

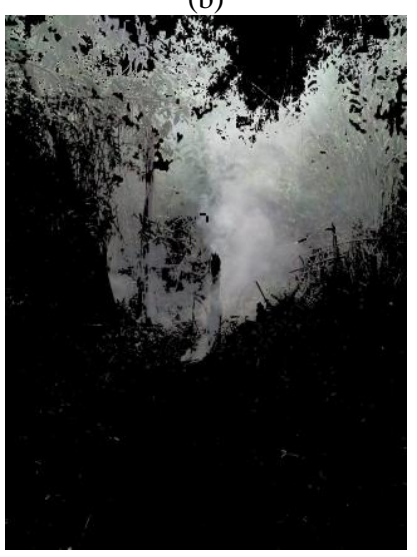

(d)

Gambar 7 (a) Citra asap asli; (b) Output Aturan I; (c) Output Aturan II; (d) Output Aturan III.

Hasil dari dari seluruh pengujian ini terlihat dalam tabel confusion matrix berikut.

Tabel 7 Confusion matrix hasil pengujian klasifikasi api

\begin{tabular}{|l|l|l|}
\hline \multirow{2}{*}{} & \multicolumn{3}{|c|}{ True Values } \\
\cline { 2 - 3 } & True & False \\
\hline
\end{tabular}




\begin{tabular}{|c|c|c|c|}
\hline 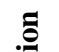 & True & 13 & 4 \\
\hline 离 & False & 2 & 1 \\
\hline
\end{tabular}

$$
\begin{gathered}
\text { accuracy }=\frac{13+1}{13+1+4+2}=\frac{14}{20}=0,7=70 \% \\
\text { precision }=\frac{13}{13+1}=\frac{13}{14}=0,92=92 \% \\
\text { recall }=\frac{13}{13+2}=\frac{13}{15}=0,87=87 \%
\end{gathered}
$$

\section{Kesimpulan}

1) Dalam proses gambar dalam aplikasi, terkadang metadata lokasi masih gagal didapatkan. Hal ini dapat diatasi dengan menambahkan proses geotag untuk menambahkan metadata lokasi ke dalam foto. Data lokasi yang ditambahkan didapatkan dari lokasi terkini ponsel saat membuka halaman map.

2) Hasil pengujian proses klasifikasi api mendapatkan nilai accuracy sebesar $75 \%$, precision sebesar $80 \%$ dan recall sebesar $80 \%$.

3) Hasil pengujian proses klasifikasi asap mendapatkan nilai accuracy sebesar $70 \%$, precision sebesar $92 \%$ dan recall sebesar $87 \%$

4) Hasil pengolahan citra masih terdapat false detection. Hal ini dikarenakan metode color filtering mengklasifikasi setiap piksel warna dari citra inputan. Sehingga mengakibatkan banyak piksel yang bukan merupakan citra api maupun asap ikut terklasifikasi karena terdapat objek lainnya yang memiliki range warna untuk mengklasifikasi api dan asap gambar. Tentunya banyak kesamaan dengan warna lain selain warna asap maupun api.

5) Penggunaan admin sebagai aktor untuk validasi akhir dari laporan titik api yang dapat berjalan dengan baik.

\section{Ucapan Terimakasih}

Elemenesia selaku pemberi Beasiswa Penelitian Elemenesia 2020 yang membantu dari segi biaya yang diperlukan peneliti untuk menyelesaikan penelitian ini.

\section{Daftar Pustaka}

[1] Lapan, "Informasi Titik Panas ( Hotspot ) Kebakaran Hutan / Lahan," vol. ISBN 978-6, 2016, [Online]. Available:

https://www.google.co.id/url?sa=t\&rct=j\&q=\&esrc=s\&source=web\&cd=3\&cad=rja\&uact=8\&ved=0ah UKEwim48Ke0_nOAhWHQo8KHfjdB7sQFggtMAI\&url=http://pusfatja.lapan.go.id/files_uploads_ebo ok/publikasi/Panduan_hotspot_2016 versi draft 1_LAPAN.pdf\&usg=AFQjCNHM3Ydg.

[2] A. Phillips and C. Steuart, "Guide to Computer Forensics and Investigations: Processing Digital Evidence Fifth Edition." .

[3] A. S. Putri and G. E. Setyawan, "Sistem Deteksi Warna pada Quadcopter Ar . Drone Menggunakan Metode Color Filtering Hue Saturation and Value ( HSV )," J. Pengemb. Teknol. Inf. dan Ilmu Komput. Univ. Brawijaya, vol. 2, no. 9, pp. 3202-3207, 2018.

[4] A. Mardani, "Sistem Informasi Geografis Pelaporan Masyarakat (SIGMA) Berbasis Foto Geotag," $J$. Sist. Dan Teknol. Inf., vol. 3, no. Vol 3, No 1 (2014), 2014.

[5] A. Susanto, "Sistem Reaksi Cepat Satgas Desa Dalam Pelaporan Kebakaran Lahan Dan Hutan Berbasis Android," Pros. SNATIF Ke-3 Tahun 2016, vol. 3, pp. 339-346, 2016. 


\section{JURNAL TEKNOLOGI INFORMASI}

Jurnal Keilmutan dan Aplikasi Biciang Teknik Informatika

[E-ISSN 2656-0321]

[Vol 15 No 1]

[ Januari 2021]

[6] C. E. Premal and S. S. Vinsley, "Image processing based forest fire detection using YCbCr colour model," 2014 Int. Conf. Circuits, Power Comput. Technol. ICCPCT 2014, pp. 1229-1237, 2014, doi: 10.1109/ICCPCT.2014.7054883.

[7] MD. Kamrujjaman Sarker, "Smoke Detection Using Image Processing," 2016.

[8] K. S. Nugroho, "Confusion Matrix untuk Evaluasi Model pada Supervised Learning | by Kuncahyo Setyo Nugroho | Medium," Medium. 2019, [Online]. Available: https://medium.com/@ksnugroho/confusion-matrix-untuk-evaluasi-model-pada-unsupervised-machinelearning-bc4b1ae9ae3f.

[9] Pressman, Roger S., and Bruce R. Maxim. "Software Engineering: A Practitioner's Approach". New York: McGraw-Hill Higher Education, 2015.

[10] V. Vipin, "Image Processing Based Forest Fire Detection,” Int. J. Emerg. Technol. Adv. Eng., vol. 2, no. 2, pp. 87-95, 2012.

[11] "Rumus Standar Deviasi - Cara Menghitung dan Contoh Soal." [Online]. Available: https://www.dosenpendidikan.co.id/rumus-standar-deviasi/.

[12] M. Swedia, Ericks Rachmat \& Cahyanti, "Algoritma Tranformasi Ruang Warna," Vis. Bassic6, Vis. Basic.NET dan java, pp. 1-7, 2010.

[13] W. A. Prasetyo, "Konversi RGB ke Grayscale." 2019, [Online]. Available: https://medium.com/@wahyuadjieprasetyo/konversi-rgb-ke-greyscale-6a9253c9a23.

[14] R.Teguh, "Study on Monitoring System for Forest Fires Based on Wireless Sensor Networks." 2014, doi:10.14943/doctoral.k11525.

[15] A. Lestari, G. Rumantir, N. Tapper, B. Saharjo, A. Usup, L. Graham, A.P. Vayda, N. Yulianti and R. Teguh, "Analysing Causal Factors of Peatland Wildfires: A Knowledge-based Approach," 2018, [Online]. Available: https://aisel.aisnet.org/pacis2018/276. 